\title{
Editorial
}

\section{Open Access: Is There a Predator at the Door?}

\author{
Rakesh Chandra, MD ${ }^{1}$ Edward W. Fisher, MA, DM (Oxon), FRCS ${ }^{2}$ \\ Terry M. Jones, BSc(Hons), MBBS, FRCSEd, FRCS(ORL-HNS), MD ${ }^{3}$ David W. Kennedy, MD 4 \\ Dennis H. Kraus, MD, FACS ${ }^{5}$ John H. Krouse, MD, PhD, MBA ${ }^{6,7}$ Michael J. Link, MD ${ }^{8}$ \\ Lawrence R. Lustig, MD ${ }^{9}$ Bert W. O’Malley, Jr., MD ${ }^{10}$ Jay F. Piccirillo, MD, FACS ${ }^{11}$ \\ Robert Ruben, MD, FAAP, FACS ${ }^{12}$ Robert T. Sataloff, MD, DMA, FACS ${ }^{13,14}$ Raj Sindwani, MD ${ }^{15}$ \\ Richard J. Smith, MD ${ }^{16}$ Michael G. Stewart, MD, MPH, FACS ${ }^{17}$ Peter C. Weber, MD ${ }^{18}$ \\ D. Bradley Welling, MD, PhD, FACS ${ }^{19}$ Robin Youngs, MB BS, MD, FRCS 20
}

\footnotetext{
${ }^{1}$ Co-Editor-in-Chief, American Journal of Rhinology and Allergy

${ }^{2}$ Senior Editor, Journal of Laryngology and Otology

${ }^{3}$ Editor-in-Chief, Clinical Otolaryngology

${ }^{4}$ Editor-in-Chief, International Forum of Allergy \& Rhinology

${ }^{5}$ Co-Editor-in-Chief, Journal of Neurological Surgery-Part B

${ }^{6}$ Editor-in-Chief, Otolaryngology-Head and Neck Surgery

${ }^{7}$ Editor-in-Chief, OTO-Open

${ }^{8}$ Co-Editor-in-Chief, Journal of Neurological Surgery-Part B

${ }^{9}$ Editor-in-Chief, Otology \& Neurotology

${ }^{10}$ Editor-in-Chief, Journal for Oto-Rhino-Laryngology, Head and Neck Surgery

${ }^{11}$ Editor-in-Chief, JAMA Otolaryngology-Head \& Neck Surgery
}

\author{
12 Editor-in-Chief, International Journal of Pediatric \\ Otorhinolaryngology \\ 13 Editor-in-Chief, Journal of Voice \\ ${ }^{14}$ Editor-in-Chief, Ear, Nose and Throat Journal \\ ${ }^{15}$ Co-Editor-in-Chief, American Journal of Rhinology \& Allergy \\ ${ }^{16}$ Editor-in-Chief, Annals of Otology, Rhinology \& Laryngology \\ 17 Editor-in-Chief, The Laryngoscope \\ ${ }^{18}$ Editor-in-Chief, American Journal of Otolaryngology \\ ${ }^{19}$ Editor-in-Chief, Laryngoscope Investigative Otolaryngology \\ ${ }^{20}$ Senior Editor, Journal of Laryngology and Otology
}

J Neurol Surg B 2018;79:115-116.

If your inbox looks like ours, you are barraged daily with requests to send research to a new journal or to join a new editorial board. Many of these "invitations" are from new open access journals, not all of which are legitimate.

Open access journals play an increasingly important role in today's world of medical publication and provide information which would otherwise be difficult or impossible for some to access. Openly sharing peer-reviewed information at no cost to the reader can greatly enhance distribution of legitimate scientific and clinical data. However, there is also an increasing number of journals purporting to serve this mission but acting in a predatory fashion. Here are a few guidelines.

Hallmarks of legitimate journals include:

- A well-known editorial board of recognized experts in the field.

- An International Standard Serial Number (ISSN).

- Listing in the Directory of Open Access Journals at https:// doaj.org.

- Publisher membership in the Open Access Scholarly Publishers Association.

- Affiliation with recognized societies.
Address for correspondence Dennis H. Kraus, MD, FACS, Co-Editor-in-Chief, Journal of Neurological Surgery-Part B (e-mail: dkraus@northwell.edu).
DOI https://doi.org/ $10.1055 / \mathrm{s}-0037-1609057$. ISSN 2193-6331.
(C) 2018 The owners of the American Journal of Otolaryngology, American Journal of Rhinology \& Allergy, Annals of Otology, Rhinology \& Laryngology, Clinical Otolaryngology, International Forum of Allergy \& Rhinology, International Journal of Pediatric Otorhinolaryngology, JAMA Otolaryngology-Head \& Neck Surgery, Journal for Oto-Rhino-Laryngology, Head and Neck Surgery, Journal of Laryngology and Otology, Journal of Neurological Surgery-Part B, Journal of Voice; Ear, Nose and Throat Journal, Laryngoscope Investigative Otolaryngology, OTO Open, Otolaryngology-Head and Neck Surgery, Otology \& Neurotology, The Laryngoscope. 
- The journal Web site provides complete contact information.

- All publication fees are clearly listed and are not submission fees.

What defines a predatory journal? Moher and Moher recently summed up the characteristics neatly by suggesting that such publications can, perhaps, be characterized by their behavior: aggressive recruitment emails, unrealistic promises regarding publication, and ultimately worthless peer review. $^{1}$

A number of published articles suggest the lack of an editorial review process as a key characteristic of predatory journal publications. One article described predatory journal publications as "gobbledegook."2 Massachusetts Institute of Technology (MIT) researchers in 2005 invented software called SCIgen, which randomly combined strings of words to produce fake computer-generated science papers that were ultimately published in open access journals. This exercise was performed to show the low bar for acceptance of papers, which were meaningless, or as they put it, "to maximize amusement." In 2014, Van Noorden pointed out in Nature News that several publishers were removing more than 120 papers from their subscription services after it was discovered that "the works were computer-generated nonsense." ${ }^{3}$

More subtle forms of nongibberish, but also nonpeerreviewed publications, seem to be expanding rapidly. Rather than motivation of the publisher to promote the science and practice of medicine, the impetus is clearly financial. They charge large sums of money to publish articles unable to pass a rigorous editorial or peer review process, which can be quite lucrative. Likewise, authors who may have been rejected by legitimate peer-reviewed journals may find that some open access journals offer an avenue for publication without editorial oversight. Therefore, we suggest the following guidelines when evaluating whether a journal is predatory.

Be cautious if:

- Invitations to submit research or to join Editorial Boards are overly flattering.

- There is a guarantee of rapid publication.

- The journals' titles are very similar to those of legitimate journals, but are not established journals.

- The journal Web site has no address or contact information.

- The mission of the publisher and/or the journal is described in vague terms.

- There is no mention of peer-review or basic submission requirements.

- Manuscripts are submitted by email rather than through the publisher's online manuscript peer-review system.

- There is a requirement to submit a minimum number of articles per year, and there is no clear statement that your open access publication fee will be waived.

We recommend an excellent recent editorial by Roberts, which shares our opinion entitled "Predatory Journals: Think before you submit." 4

Our goal is to provide high-quality, rigorously peerreviewed papers and scientific information of value to you and all of our readers.

\section{References}

1 Moher D, Moher E. Stop predatory publishers now: act collaboratively. Ann Intern Med 2016;164(09):616-617

2 Ball P. Computer conference welcomes gobbledegook paper. Nature 2005;434(7036):946

3 Van Noorden R. Publishers withdraw more than 120 gibberish papers. NATNEWS; 2014

4 Roberts J. Predatory Journals: think before you submit. Headache 2016;56(04):618-621 